\title{
СПЕЦИФИКА ФОРМИРОВАНИЯ СОВРЕМЕННОГО РОССИЙСКОГО И ЗАПАДНОГО МЕНЕДЖМЕНТА
}

\section{(c) 2020 Буртонова Галина Борисовна}

кандидат экономических наук, доцент кафедры «Менеджмент, маркетинг и коммерция» Восточно-Сибирский государственный университет технологий и управления, Россия, Улан-Удэ E-mail: burtonovagalya@yandex.ru

\section{(C) 2020 Желаева Светлана Эдуардовна}

доктор экономических наук, доцент, заведующий кафедрой «Менеджмент, маркетинг и коммерция»

Восточно-Сибирский государственный университет технологий и управления, Россия, Улан-Удэ E-mail: zhelay@yandex.ru

\section{(c) 2020 Хамаганова Татьяна Кимовна}

кандидат экономических наук, доцент кафедры «Менеджмент, маркетинг и коммерция» Восточно-Сибирский государственный университет технологий и управления, Россия, Улан-Удэ

$$
\text { E-mail: x_tk@mail.ru }
$$

В статье рассматривается специфика формирования российского менеджмента в XXI в. Прослеживаются и сравниваются особенности традиционного (советского) менеджмента, современного российского и западного менеджмента, которые также сопоставляются с моделью самообучающейся организации, что позволяет нам сделать вывод о возрастании роли интеллектуальных ресурсов менеджмента в управлении современными предприятиями. Интеллектуальные ресурсы основаны на человеческом капитале коллектива, который задействован в процессах производства продукции, взаимодействии с руководством, создании инноваций. Развитие интеллектуальных ресурсов организации становится объектом нового менеджмента, условием инновационного развития и повышения конкурентоспособности, условием формирования самообучающейся организации.

Ключевые слова: этапы развития менеджмента, западный менеджмент, российский менеджмент, традиционный менеджмент, самообучающаяся организация.

История российского менеджмента так же как и рыночной экономики значительно коротка по сравнению с западной. Становление российского менеджмента с конца XX века основано на процессах копирования западных моделей с учетом опыта собственного прошлого. Менеджмент российских предприятий обладает своим собственным национальным менталитетом, который отличается от западных моделей и, несмотря на многолетние попытки его копирования, остается в действии. Западные модели менеджмента между тем эволюционируют и появляются новые модели организаций, демонстрирующие свои превосходящие признаки. В статье мы попытаемся сопоставить основные признаки отечественной традиционной модели, современной российской модели, обобщенной западной модели менеджмента и сравнить их с моделью самообучающейся организации, зародившейся в 80-90-х гг. прошлого столетия как попытки западного менеджмента пересмотреть подходы к управлению в условиях нарастающих кризисных явлений в обществе, экономике и экологии.

Многим стало ясно, что традиционные методы управления нуждаются в обновлении. В сфере бизнеса рост неопределенности, экономические и политические потрясения, растущая взаимозависимость мировых рынков и мировых корпораций породили призыв к радикальным изменениям. В обществе в целом растет понимание того, что имеющиеся тенденции к росту потребления и загрязнения окружающей среды, растущие дезинтеграция и неуправляемость представляют собой беспрецедентную угрозу для будущего. Сегодня многие признают, что нам нужна куда большая способность учиться, чем могут обеспечить традиционные авторитарно-иерархические организации [1].

Впервые концепции самообучающейся ор- 
ганизации зародились в работах, выполненных в Массачусетском Технологическом институте в конце 1980-х гг. Теоретическими основами этой концепции стали различные теории: теория самообновления (Дж.Гарднер); теория организационного обновления (Г.Липпит); концепция обучающихся систем (Д.Шон) и др.

Само понятие «самообучающейся организации» было введено в оборот П.Сенге. Обучающимися являются «организации, в которых люди непрерывно расширяют свои возможности достижения желательных для себя результатов, где создаются новые, способные к развитию модели мышления, где коллективное устремление является свободным и где люди непрерывно учатся возможностям совместного обучения» [1].

Исчерпание возможностей роста на основе традиционных ресурсов, кризисные явления в управлении в западных фирмах обусловили создание и зарождение новой теории самообучающейся организации, в основе которой лежит использование нетрадиционных источников ресурсов. Речь идет об интеллектуальных ресурсах, внедрение и использование которых становится базовым условием успешного развития организации и повышения эффективности управления. Под интеллектуальными ресурсами мы понимаем всю совокупность знаний, умений, навыков, психических и нравственных усилий, прилагаемых трудовыми коллективами организаций в целях эффективного развития не только организации, но и постоянного собственного совершенствования, направленного на профессиональное саморазвитие.

Эффективность современного менеджмента состоит не только в стиле руководства организациями, но и в работе самого персонала, стиле его мышления, отношении к работе, направленных на созидание и инновации, позволяющих фирме развиваться, противостоять конкуренции и глобальным вызовам.

По мнению некоторых российских исследователей, эти организации можно назвать человекоориентированными. «Современные теории управления рассматривают новые механизмы взаимодействия системы и объекта управления, предполагая, что объект управления может не только исполнять, но и занимать активную позицию по отношению к управляемой системе при условии обеспечения достижения целей как самого объекта, так и всей организации. В этом случае инициатива по изменениям и их реали- зация исходят из объекта управления, и, соответственно, становятся другими механизмы и методы управления внутри предприятия. Именно эти процессы относятся к классу саморазвивающихся. И поскольку инициатива изменений исходит от людей, то такие организации можно назвать человекоориентированными» [2].

Эволюционное развитие менеджмента на российских предприятиях происходит на протяжении почти тридцатилетнего периода и, как мы видим, определенные трансформации затронули многие стороны менеджмента. Однако такие аспекты, как авторитарный стиль руководства и подчиненное положение работников в иерархии предприятия, остаются практически неизменными.

Длительный исторический опыт существования жестко авторитарного стиля руководства заложил основополагающее влияние на становление современного менеджмента в России. «Для России традиционно было абсолютизирование личности руководителей, отстраненность коллектива от принятия решений и ответственности за их результат, отрицательное отношение к богатству и его ассоциация с несправедливостью и незаконностью» [3]. Поэтому авторитарный стиль продолжает сохраняться в значительной степени и в современный период, позиция работников в процессе принятия решений традиционно остается отстраненной.

В отличие от российского западный менеджмент не стремится доминировать во время процесса принятия решений и дискуссий, принимается во внимание мнение всех сторон, что выражает уважение и лояльность по отношению к другим сотрудникам. В крупных западных фирмах все более проявляется тенденция децентрализации - передачи части полномочий по принятию решений, включая и стратегические, подразделениям. Такая вовлеченность персонала в процесс управления ведет к росту заинтересованности, а следовательно, производительности и качества труда, к снижению издержек, повышению эффективности и отдачи инвестируемых средств. В ходе решения текущих задач западный менеджмент нацелен на согласованность мнений и учет интересов всех вовлеченных сторон, что впоследствии помогает избежать конфликтных ситуаций внутри коллектива и повысить производительность труда.

Традиция западного мышления основана на активной позиции, индивидуализме, опоре 
на собственные силы и напористости работников. Обусловлена такая традиция тем, что уже в методах воспитания с детства ребенку прививается самостоятельность, независимость и способность к конкуренции. В фирмах ценятся и менеджеры, и работники, способные проявлять инициативу и предприимчивость, являющиеся активными и имеющие собственное видение происходящих событий, имеющие свое мнение, которое они могут свободно высказать. Отсутствие активности работника и его подчинение внешним условиям, неспособность проявить свои внутренние стремления - такие качества являются серьезным недостатком для работника в западном мире.

Большие достижения имеют те работники, которые, что называется, проактивны. Неактивные или реактивные сотрудники обычно в большей степени подвержены влиянию внешних обстоятельств и не сопротивляются негативным жизненным событиям. Поэтому западные компании стремятся собрать у себя в коллективе как можно больше проактивных людей, которые, по их мнению, помогут вывести вперед компанию. Следовательно, в западных фирмах ценится наличие у человека амбиций, составляющих обязательное профессиональное качество. В российских фирмах же амбициозность работника имеет скорее выраженный негативный оттенок. Амбициозный человек в России - это обычно тот, кто стремится всеми силами выделиться из общей массы, пренебрегает мнением окружающих, делает карьеру часто за счет окружающих. Традиционно в российском, а особенно в советском обществе, понятие «амбиции» имело негативный смысл и люди, стремящиеся выделиться из общей толпы, не имели поддержки со стороны окружения. Более того, проявление амбициозности в любой сфере не приветствовалось и даже осуждалось. Существовали даже отрицательные обозначения («выскочка», «карьерист»), которыми называли людей, проявивших в чем-либо инициативу и смелость, а тем более, открыто претендующих на карьеру и рост. Такое различие в отношении работников к карьере и обязанностям накладывает особенности на специфику российского и западного менеджмента.

Особенности российского менталитета проявляются также и в карьерном продвижении и отношении к руководителю. Так, менеджер, однажды оказавшийся на высокой руководя- щей должности, уже практически никогда не возвращается со своих руководящих постов на более низкие ступени руководства. Такие менеджеры перемещаются либо на аналогичные горизонтальные должности, либо выше. Вступив в эшелон руководства, он уже не подлежит понижению в должности, как бы неэффективно он не работал. Психология власти заменяет психологию ответственности и полномочий, зачастую самым главным для руководителя становится удержание власти, которая позволяет командовать большим числом людей, перекладывая свои обязанности на других. В таких условиях позиции работников остаются отстраненными и пассивными, отношение к высшему менеджменту в целом принимает негативный оттенок, отсутствует доверие и взаимопонимание.

Одним из несомненных факторов повышения эффективности работы лидера и характерной чертой его модели поведения является стиль руководства. Выбранный стиль мышления и руководства обусловлен необходимостью постоянно искать нетрадиционные и инновационные пути развития предприятия, потребностями в обеспечении стабильности и конкурентоспособности в современной волатильной бизнес-среде. От стиля управления зависит психологическая обстановка в организации, создается или не создается атмосфера, способствующая творческой работе коллектива и полной отдаче работников. Так, свободный демократический стиль общения и демократическая атмосфера в коллективе создают доверительную среду, возможности каждого быть услышанным, владеть необходимой информацией и видеть множество альтернативных путей развития организации и возможных решений. Работники могут анализировать каждое, с точки зрения отсроченного эффекта и своевременного перехода к действию, решение, а также быть готовыми к быстрой смене курса. Характерной чертой и одной из составляющей успеха западного менеджмента является то, что предпочитается коллегиальный, сотрудничающий стиль взаимодействия с другими людьми в процессе принятия решения, опирающийся на мнения различных людей, и целенаправленно создающий обстановку, благоприятную для свободного развития и выражения взглядов сотрудников. Западный стиль управления, осознавая эти преимущества, применяет демократические приемы и методы на практике, что особенно эффективно в работе коллективов, занятых творче- 
ской, научной и инновационной деятельностью.

Российский менеджмент действует наоборот, опираясь на прежний во многом авторитарный стиль руководства. Для России наиболее характерным был жесткий стиль управления компанией - четкое выполнение всех приказов, иерархическая структура подчинения, отсутствие возможностей и каналов для выражения иной точки зрения, отсутствие обратной связи и т.д. Такой стиль управления оправдывает себя только в определенных условиях, в определенных сферах, но в течение длительного периода времени он не оправдывает себя, так как не способствует ни творческому, ни инновационному развитию работников и организации в целом, ведет к ее стагнации и потере конкурентоспособности.

Множественные проблемы и глобальные вызовы современной реальности обусловили формирование своеобразной модели управления, которая в определенной степени сохраняет традиционные черты прошлого и интегрирует новые черты, заимствованные из западных моделей. На наш взгляд, наиболее устойчивым признаком прошлого остаются подходы к внутри- фирменным коммуникациям. Так, положение работников жестко определено иерархическими рамками, рядовые сотрудники являются лишь простыми исполнителями, не способными и не заинтересованными в проявлении инициативы, которая чаще всего не приветствуется. Сфера производственных отношений, затрагивающая взаимодействие руководства и подчиненных, является самой мало подверженной изменениям видом коммуникаций в любом коллективе.

Рассмотрим различные модели менеджмента (таблица 1), сравнив их по разным признакам и сопоставив с самообучающейся моделью организации.

Сравнительный анализ моделей показывает, что модель традиционных «советских» методов управления еще не полностью изжитая на практике, по многим позициям уступает западным моделям, более того, находится в зачаточном состоянии по отношению к самообучающейся модели организации. Самообучающаяся модель организации основана на механизмах и методах, использующих в большей степени интеллектуальные ресурсы и интеллектуальный характер

Таблица 1. Сравнительный анализ различных моделей менеджмента

\begin{tabular}{|c|c|c|c|c|}
\hline Признаки & $\begin{array}{c}\text { Модель «традицион- } \\
\text { ных (советских) ме- } \\
\text { тодов управления» }\end{array}$ & $\begin{array}{c}\text { Современная } \\
\text { российская модель }\end{array}$ & Западные модели & $\begin{array}{c}\text { Самообучающаяся } \\
\text { модель организации }\end{array}$ \\
\hline $\begin{array}{l}\text { 1. Подходы к стра- } \\
\text { тегии }\end{array}$ & $\begin{array}{l}\text { Стратегия и тактика } \\
\text { развития предпри- } \\
\text { ятия установлены } \\
\text { заранее, они едины, } \\
\text { представляют } \\
\text { собой неизменный } \\
\text { вариант, принятый в } \\
\text { данной среде. }\end{array}$ & $\begin{array}{l}\text { Стратегия и тактика } \\
\text { компании являются } \\
\text { в некоторой мере } \\
\text { гибкими, могут быть } \\
\text { изменены с учетом } \\
\text { происходящих из- } \\
\text { менений во вну- } \\
\text { тренней и внешней } \\
\text { среде организации. }\end{array}$ & $\begin{array}{l}\text { Стратегия и тактика } \\
\text { компании являются } \\
\text { достаточно гиб- } \\
\text { кими, могут быть } \\
\text { изменены с учетом } \\
\text { происходящих } \\
\text { изменений во вну- } \\
\text { тренней и внешней } \\
\text { среде организации. }\end{array}$ & $\begin{array}{l}\text { Подход к стратегии } \\
\text { гибкий. Стратегия и } \\
\text { тактика компании } \\
\text { рассматриваются } \\
\text { как процессы, кото- } \\
\text { рые могут меняться, } \\
\text { совершенствуясь } \\
\text { с учетом происхо- } \\
\text { дящих изменений } \\
\text { во внутренней и } \\
\text { внешней среде орга- } \\
\text { низации. }\end{array}$ \\
\hline $\begin{array}{l}\text { 2. Политика управ- } \\
\text { ления, процесс } \\
\text { принятия решений }\end{array}$ & $\begin{array}{l}\text { Решения принимает } \\
\text { руководитель, что } \\
\text { основано на прави- } \\
\text { лах и инструкциях. } \\
\text { Работники лишены } \\
\text { права принимать } \\
\text { решения и являются } \\
\text { только исполните- } \\
\text { лями. } \\
\text { Одноцелевое плани- } \\
\text { рование, без учета } \\
\text { возможных измене- } \\
\text { ний. }\end{array}$ & $\begin{array}{l}\text { Решения принима- } \\
\text { ются руководством. } \\
\text { Работники могут } \\
\text { принимать уча- } \\
\text { стие в обсуждении } \\
\text { проблем, но оконча- } \\
\text { тельное слово оста- } \\
\text { ется за руководите- } \\
\text { лем. Многоцелевое } \\
\text { планирование. }\end{array}$ & $\begin{array}{l}\text { В зависимости от } \\
\text { конкретной модели } \\
\text { практика приня- } \\
\text { тия ответственных } \\
\text { решений коллектив- } \\
\text { ная, но окончатель- } \\
\text { ное слово принадле- } \\
\text { жит руководителю. } \\
\text { Многоцелевое пла- } \\
\text { нирование. }\end{array}$ & $\begin{array}{l}\text { Работники ши- } \\
\text { роко вовлечены в } \\
\text { процесс принятия } \\
\text { решений. Работник } \\
\text { имеет право на } \\
\text { самостоятельное } \\
\text { решение в пределах } \\
\text { его работы. Цели и } \\
\text { задачи организации } \\
\text { и организацион- } \\
\text { ных единиц могут } \\
\text { обсуждаться между } \\
\text { работниками. Воз- } \\
\text { можность работни- } \\
\text { ков для обсуждения } \\
\text { и анализа ошибок. }\end{array}$ \\
\hline
\end{tabular}




\begin{tabular}{|c|c|c|c|c|}
\hline $\begin{array}{l}\text { 3. Отношение к } \\
\text { работе, карьере }\end{array}$ & $\begin{array}{l}\text { Пассивная позиция } \\
\text { работников, от- } \\
\text { сутствие амбиций, } \\
\text { осуждение слишком } \\
\text { активных выделяю- } \\
\text { щихся людей. }\end{array}$ & $\begin{array}{l}\text { Чаще пассивная } \\
\text { позиция работни- } \\
\text { ков, недостаточные } \\
\text { амбиции, неуверен- } \\
\text { ность в своей воз- } \\
\text { можности что-либо } \\
\text { изменить. }\end{array}$ & $\begin{array}{l}\text { Активная позиция } \\
\text { работников, доста- } \\
\text { точные амбиции и } \\
\text { уверенность в себе и } \\
\text { в своих силах. }\end{array}$ & $\begin{array}{l}\text { Активная позиция } \\
\text { работников, уве- } \\
\text { ренность в себе, } \\
\text { свободное выраже- } \\
\text { ние своих мыслей, } \\
\text { амбиции и уверен- } \\
\text { ность в своих силах } \\
\text { что-либо изменить. }\end{array}$ \\
\hline $\begin{array}{l}\text { 4. Доступ к инфор- } \\
\text { мации }\end{array}$ & $\begin{array}{l}\text { Значительная } \\
\text { часть информации } \\
\text { засекречена, никто } \\
\text { из работников не } \\
\text { видит всю картину в } \\
\text { целом и не обладает } \\
\text { полной информа- } \\
\text { цией. }\end{array}$ & $\begin{array}{l}\text { Доступ к информа- } \\
\text { ции имеют лишь } \\
\text { руководящие кадры, } \\
\text { рядовые сотрудники } \\
\text { получают только } \\
\text { необходимую для } \\
\text { выполнения их } \\
\text { работы информа- } \\
\text { цию, что сужает их } \\
\text { возможности. }\end{array}$ & $\begin{array}{l}\text { Доступ к информа- } \\
\text { ции имеют лишь } \\
\text { руководящие кадры, } \\
\text { рядовые сотрудники } \\
\text { получают только } \\
\text { необходимую для } \\
\text { выполнения их } \\
\text { работы информа- } \\
\text { цию, что сужает их } \\
\text { возможности. }\end{array}$ & $\begin{array}{l}\text { Информация в } \\
\text { свободном доступе, } \\
\text { широко использу- } \\
\text { ется для принятия } \\
\text { правильных реше- } \\
\text { ний. Развитие широ- } \\
\text { кой сети коммуни- } \\
\text { каций между всеми } \\
\text { организационными } \\
\text { единицами и их } \\
\text { членами. }\end{array}$ \\
\hline $\begin{array}{l}\text { 5. Система вну- } \\
\text { трифирменных } \\
\text { отношений }\end{array}$ & $\begin{array}{l}\text { Разногласия в кол- } \\
\text { лективе не допуска- } \\
\text { ются, конфликты } \\
\text { рассматриваются } \\
\text { как деструктивные } \\
\text { процессы и должны } \\
\text { быть устранены. Ме- } \\
\text { неджер использует } \\
\text { жестко авторитар- } \\
\text { ный стиль руковод- } \\
\text { ства. }\end{array}$ & $\begin{array}{l}\text { Конфликты рас- } \\
\text { сматриваются как } \\
\text { деструктивные } \\
\text { процессы и должны } \\
\text { быть устранены. } \\
\text { Авторитарный стиль } \\
\text { руководства, подчи- } \\
\text { ненные полностью } \\
\text { зависимы от руко- } \\
\text { водства. }\end{array}$ & $\begin{array}{l}\text { Конфликты рас- } \\
\text { сматриваются как } \\
\text { деструктивные } \\
\text { процессы и должны } \\
\text { быть устранены. } \\
\text { Во многом демо- } \\
\text { кратический стиль } \\
\text { руководства, подчи- } \\
\text { ненные могут выра- } \\
\text { жать свое мнение. }\end{array}$ & $\begin{array}{l}\text { Отношения в кол- } \\
\text { лективе основаны } \\
\text { на доверии и пар- } \\
\text { тнерстве. Возмож-- } \\
\text { ны разногласия во } \\
\text { мнениях, дискуссии } \\
\text { и свободный обмен } \\
\text { идеями. Отношения } \\
\text { построены на коопе- } \\
\text { рации и сотрудни- } \\
\text { честве. }\end{array}$ \\
\hline 6. Внешняя среда & $\begin{array}{l}\text { Явный интерес } \\
\text { к внешней среде } \\
\text { отсутствует, нет } \\
\text { необходимости ее } \\
\text { изучать, так как } \\
\text { изменения в окру- } \\
\text { жении организации } \\
\text { особо не отражаются } \\
\text { на ее состоянии. }\end{array}$ & $\begin{array}{l}\text { Постоянно изу- } \\
\text { чается состояние } \\
\text { внешней среды, } \\
\text { происходит сбор } \\
\text { информации с це-- } \\
\text { лью своевременной } \\
\text { реакции на происхо- } \\
\text { дящие изменения в } \\
\text { рыночной среде. }\end{array}$ & $\begin{array}{l}\text { Активно изучается } \\
\text { состояние внеш- } \\
\text { ней среды, анализ } \\
\text { всей поступающей } \\
\text { информации для } \\
\text { быстрой реакции } \\
\text { на происходящие } \\
\text { изменения в рыноч- } \\
\text { ной среде. }\end{array}$ & $\begin{array}{l}\text { Работники следят за } \\
\text { тем, что делается за } \\
\text { пределами орга- } \\
\text { низации, с целью } \\
\text { быстрого и адекват- } \\
\text { ного реагирования } \\
\text { на происходящие } \\
\text { изменения во внеш- } \\
\text { ней среде. События } \\
\text { внешней среды } \\
\text { анализируются. }\end{array}$ \\
\hline
\end{tabular}

принятия решений, многоуровневое лидерство с вовлечением широкого числа работников, внутреннее предпринимательство и инициативу работников, которые находятся в отношениях партнерства, основанных на доверии, взаимопонимании и сотрудничестве. Инициатива персонала проявляется в возможности широко обсуждать проблемы, стараться извлекать полезный опыт из ошибок и приходить к разумным компромиссным решениям.

Значительны различия и в стратегии. В командной модели существует жесткий подход к стратегии, которая определена и задана заранее. Стратегия и тактика развития предприятия установлены по стандартам, они едины и представляют собой неизменно принятый вариант. В западной и самообучающейся моделях подходы к стратегии гибкие. Стратегия и тактика компании рассматриваются как процессы, которые могут меняться, совершенствуясь с учетом происходящих изменений во внутренней и внешней среде организации.

В политике управления и принятия решений также прослеживаются значительные различия. В командной модели решения менеджера основаны на правилах, нормах и инструкциях. Работники лишены права принимать решения и являются только слепыми исполнителями. Отсюда пассивная позиция работников, отсутствует стремление проявлять самостоятельность и инициативу. Тогда как в западной модели, наоборот, все работники широко вовлечены в процесс принятия решений, каждый имеет право на самостоятельное решение в пределах его 
компетенции. Цели и задачи организации и организационных единиц широко обсуждаются между всеми членами организации. Еще в конце двадцатого века один из основоположников менеджмента П.Друкер, поднимая проблему внутренних коммуникаций между руководителем и подчиненными и осознавая их важность, сравнивал эти взаимодействия с работой оркестра. «В современных условиях взаимоотношения «начальника» и «подчиненных» больше напоминают взаимоотношения дирижера оркестра и музыканта, а не традиционную схему «я начальник, ты дурак» [4].

По мнению П.Друкера, «разными группами работников нужно управлять по-разному; одной и той же группой работников следует управлять по-разному в разных ситуациях. Все чаще «служащими» следует управлять как «партнерами», а партнерство уже исключает «управление», поскольку предполагает равенство участников. Партнеры не могут приказывать друг другу. Они могут только убеждать друг друга» [4]. Такие подходы к управлению становятся неотъемлемой частью внутреннего взаимодействия в самообучающейся организации. Появление теории самообучающейся организации обусловлено в то числе и системным кризисом западного менеджмента, который также исчерпал свои возможности и нуждается в качественном обновлении. Современный западный менеджмент часто оказывается не в состоянии решать усложняющиеся задачи бизнеса и справляться с агрессивными вызовами внешней среды, вызванными глобальными проблемами и нестабильностью внешней среды.

«Внешняя среда характеризуется как турбулентная, неустойчивая, а традиционные методы менеджмента успешно работают в условиях высокой степени определенности, что не характерно в последнее время, и эта тенденция сохранится. Рост волатильности и динамики рынков, сокращение жизненных циклов продукции формируют новые требования к системе управления» [5].

Сравнение по всем прочим позициям демонстрирует значительные различия между моделями, что обусловлено многими факторами: традициями, культурными особенностями, различиями в эволюционным путях развития экономики, менталитетом работников, идеологическими подходами и многими другими.
Одно из основных отличий западного менеджмента и менеджмента самообучающейся организации состоит в интеллектуальном характере многих процессов, в том числе и принятия решений. Так, происходит качественное изменение менеджмента, преобладание механизмов и методов, основанных на поведенческой мотивации, многоуровневом лидерстве работников, разумных компромиссах, предприимчивости, активности и инициативе работников. Персонал проявляет инициативу, заинтересован и имеет возможность принимать участие в обсуждении проблем. В организации задействованы больше интеллектуальные ресурсы, которые занимаются многоцелевым планированием, учитывающим противоречивость принимаемых управленческих решений и их различные последствия, могут из ошибок извлекать уроки и учиться на них. Так, решения, эффективные в одной сфере, могут вызвать негативные последствия или снижение эффективности в других сферах. В традиционной модели управления многоцелевой фактор практически не учитывается. Если планируются несколько целей, они рассматриваются отдельно, как набор целей, а не в комплексе, и планирование осуществляется по готовым стандартам, что неизбежно приводит к ошибкам и снижению эффективности.

Также обязательным условием самообучающейся модели и передового западного менеджмента является наличие непрерывных инновационных процессов внутри организации. Инновации должны создаваться не только специализированными отделами и службами по исследованию и разработкам, но и превратиться в главные ежедневные инструменты роста внутренней эффективности и конкурентоспособности всех подразделений. Развитие любой современной организации без опоры на инновации, в том числе и в управлении, приводит к утере своих позиций и снижению эффективности. Стремление к профессиональному росту и постоянному обучению и саморазвитию персонала создает основу для развития передовых технологий и внедрения инноваций. Непрерывное обучение и самообучение являются новыми функциями менеджера в условиях быстрого обновления производств, продуктов, появления новых методов и технологий управления. Наряду с этим широко используются информационные технологии, являющиеся фактором инновационного развития. 


\section{Библиографический список}

1. Сенге П. Пятая дисциплина: Искусство и практика самообучающейся организации. М.: ЗАО «ОлимпБизнес», 2003. С.10.

2. Комаров С.В., Молодчик А. В. Понятие саморазвивающейся локальной организации и новая теория менеджмента. Бизнес. Образование. Право. Вестник Волгоградского института бизнеса, 2012, № 3 (20). С.198.

3. Иванова Т.Б. Сравнительный анализ российского и западного менеджмента в современных условиях. Экономика и право, 2016. № 7 (65). С.20-23.

4. Друкер, Питер, Ф. Задачи менеджмента в XXI веке.: Пер. с англ.:- М.: Издательский дом «Вильямс», 2004. 272 c.

5. Антонов В.Г. Проблемы и перспективы развития менеджмента в России. Управление № 4 (14) / $2016.104:$ C. 6-15. 